\title{
Majority of drug-related problems identified during medication review are not associated with STOPP/START criteria
}

\author{
Sanne Verdoorn ${ }^{1,2} \cdot$ Henk-Frans Kwint ${ }^{1,2}$ • Adrianne Faber ${ }^{2}$. Jacobijn Gussekloo ${ }^{3}$. \\ Marcel L Bouvy ${ }^{1,2}$
}

Received: 22 April 2015 / Accepted: 13 July 2015 /Published online: 7 August 2015

(C) The Author(s) 2015. This article is published with open access at Springerlink.com

\begin{abstract}
Purpose STOPP and START criteria identify potential inappropriate prescribing and potential prescribing omissions. It is unknown whether STOPP/START criteria identify all drugrelated problems. This study aims to determine to what extent STOPP/START correspond to drug-related problems (DRPs) identified during a full clinical medication review.

Methods In 13 Dutch community pharmacies, 457 community-dwelling patients aged $\geq 65$ years and using $\geq 5$ drugs, received a full clinical medication review. Community pharmacists identified potential DRPs and recommendations by implicit criteria. After completion, all identified DRPs and recommendations were compared with STOPP and START criteria by investigators.

Results The total number of potential DRPs identified by community pharmacists was 1656 in 457 patients (mean 3.6 per patient). Eighty-one percent of DRPs were not associated with STOPP/START criteria. The percentage of START criteria present in identified DRPs was higher than the percentage of STOPP criteria ( 13 vs. $5.7 \%, p<0.01$ ).

The implementation rate for recommendations associated with STOPP criteria was higher compared to recommendations associated with START criteria (56 vs. $39 \%, p<0.01$ ).
\end{abstract}

Sanne Verdoorn

s.verdoorn@stevenshof.nl

1 Division of Pharmacoepidemiology \& Clinical Pharmacology,

Utrecht Institute for Pharmaceutical Sciences (UIPS),

3584 CG Utrecht, The Netherlands

2 SIR Institute for Pharmacy Practice and Policy,

2331 JE Leiden, The Netherlands

3 Department of Public Health and Primary Care, Leiden University Medical Center, 2333 ZD Leiden, The Netherlands
Both implementation rates of STOPP and START recommendations were lower compared to recommendations not associated with STOPP/START criteria $(66 \%, p=0.047$ and $p<0.001$, respectively).

Conclusions This study shows that the majority of drugrelated problems of community-dwelling older patients was not associated with STOPP/START criteria. These findings suggest that application of STOPP/START criteria in full clinical medication review should preferably be combined with implicit criteria.

Keywords Medication review · Drug-related problems · STOPP/START criteria · Inappropriate prescribing · Elderly · Primary care

\section{Introduction}

Polypharmacy and inappropriate medication use by older people increase the risk of adverse drug reactions [1]. Inappropriate medications are defined as medications for which the potential risk outweighs the potential benefit [2]. Next to inappropriate medications, older patients with polypharmacy may also be susceptible to under-prescribing. Under-prescribing of medications refers to the omission of a drug when there is a clear indication and no contra-indication [3].

Several tools are available to evaluate inappropriate medication and prescribing omissions in older patients, including implicit and explicit criteria. Implicit criteria, like the Medication Appropriateness Index (MAI), consist of a structural assessment of the patient's medicines. They may rely on expert professional judgment for their application. Although implicit criteria have demonstrated their usefulness in detecting drugrelated problems in several studies, the application may be rather time-consuming in practice [4-12]. 
Explicit criteria consist of lists of inappropriate medications and prescribing omissions in the elderly. The first explicit criteria published for potentially inappropriate medications were the Beers-criteria [2, 13-15]. These are the most widely cited criteria for inappropriate medications, but the applicability outside the USA is limited due to differences in types of drugs and guidelines [16-18]. In 2008, two sets of Europeanbased criteria (STOPP and START) were formulated to address the perceived deficiencies of Beers' criteria and prescribing omissions as well [19]. Screening Tool of Older Persons Prescriptions (STOPP) contains a list of 65 potentially inappropriate medications or medication classes. Screening Tool to Alert doctors to Right Treatment (START) lists 22 potential prescribing omissions (PPOs) in patients with particular medical conditions [19].

Studies in older patients showed that STOPP criteria were more sensitive than Beers criteria in identifying potentially inappropriate medications [20-22]. However, there are no studies that compared the use of these explicit criteria with implicit criteria in the detection of drug-related problems. Therefore, the aim of our study was to determine the number and types of STOPP/START criteria present in identified drug-related problems (DRPs) and recommendations found by medication review with implicit criteria.

\section{Methods}

\section{Study procedures and population}

In 13 Dutch community pharmacies, a list of all communitydwelling patients aged 65 years and older, using at least five oral prescription drugs in 2011, was compiled using the pharmacy information system. From this list, the pharmacists took a convenience sample of patients to invite for a medication review. Pharmacies were located in both urban regions in the south-west of the Netherlands. Pharmacists received complete medical data from the general practitioners (GPs), including diagnoses and laboratory values, after agreement of the patient.

\section{Ethics}

Medication reviews are provided as an enhanced service for older people with polypharmacy by pharmacists and GPs in the Netherlands. In order to protect the patient's privacy, all data were anonymised by the community pharmacists using a randomly assigned unique number. The researchers only received the anonymised written care plans of the medication reviews. In addition, they received anonymised drug dispensing records for each patient. Because this study was performed retrospectively and used anonymised patient data, no ethical approval was required according to current Dutch guidelines.

\section{Medication review}

The patient's community pharmacist interviewed the patient about his drugs at home or in the pharmacy. Patient's concerns and experiences regarding drug therapy (in particular perception of the effectiveness and potential adverse effects), adherence issues, practical problems, understanding of their medication regimen and possible use of OTC (over the counter) medication were addressed during this interview. A pharmaceutical care plan was proposed by the community pharmacist using both the patient's medication records from the pharmacy, general practitioners (GPs) medical records and the data from the patient interview. Potential DRPs and associated recommendations were identified by implicit criteria based on a structural assessment of indication, effectiveness, safety and compliance by Hepler and Strand [7]. Recommendations were implemented after agreement between both the community pharmacist, the general practitioner and the patient. Followup of implemented recommendations was monitored by the community pharmacists.

Participating community pharmacists had experience in performing medication reviews. Therefore, they received an accredited training course in medication review. The course educated in clinical guidelines, communication skills, identifying DRPs and designing pharmaceutical care plans. In addition, pharmacists participated in monthly web conference sessions moderated by a medication review expert. During these sessions, case studies and treatment guidelines were discussed. Moreover, all pharmacists were observed and received feedback on one medication review session.

\section{Data classification}

Drugs were classified using the Anatomical Therapeutic Chemical (ATC) Classification System (11th edition, 2008) formulated by the World Health Organization Collaborating Centre for Drug Statistics Methodology. Potential DRPs and recommendations were classified according to the D.O.C.U.M.E.N.T. system by the community pharmacists $[12,23-25]$.

\section{Application of START-STOPP criteria}

After completion of the medication reviews, the anonymised results were sent to the investigators. The database with the results consisted of registered DRP's, ATC codes of the drugs associated with the DRPs and interventions, recommendations and free text boxes with reasons to change a drug (e.g. start ACE inhibitor because of heart failure). Based on these results, STOPP and START criteria were retrospectively and independently applied by two investigators (H.K. and S.V.). Differences were discussed until consensus was reached. A $10 \%$ sample of the DRPs was taken and also reviewed by 
two other investigators (A.F. and M.B.). For the application of the STOPP/START criteria, the first version of the STOPP/ START criteria was used [19]. Two adaptations of the original criteria were made to make the criteria fit the current Dutch guideline [8]. The STOPP criteria: "aspirin or NSAIDs without a proton pump inhibitor" and "opiates without laxatives", were modified to START criteria [8].

\section{Outcome measurements}

The primary outcomes were number, type and implementation rate of STOPP and START criteria applicable to identified DRPs and associated recommendations during medication review. The implementation rate was defined as the percentage of recommendations that was fully or partly implemented according to the community pharmacist.

\section{Statistical analysis}

All implementation rates of recommendations were analysed on an intention-to-treat basis. Descriptive statistics were used for basic characteristics. Pearson chi-square tests were used for each categorical variable. A $p$ value $<0.05$ was considered statistically significant. All data were analysed using Microsoft Access and Excel 2010 (Microsoft Corporation, Redmond, WA, USA) and SPSS version 20.0 (SPSS Inc., Chicago, IL, USA).

\section{Results}

\section{Demographics}

Twenty-one community pharmacists in 13 pharmacies collaborated with 65 GPs in this study. The pharmacists conducted 533 patient interviews. Clinical medication reviews were performed for 461 of 533 patients. Seventy-two patients were excluded because their medication reviews were not fully completed. Of 461, another four patients were excluded during follow-up because of death or hospital admission. Finally, 457 patients were included for analysis. The median age was 77 years (interquartile range 73-81), and $60 \%$ were women (Table 1). The most commonly prescribed drug classes were "antithrombotic agents" (69\%) and "agents acting on the renin-angiotensin system" (68 \%).

\section{STOPP and START criteria among identified DRPs}

A total of 1656 potential DRPs were identified (mean 3.6 per patient) (Table 2). Eighty-one percent of DRPs were not associated with either STOPP or START criteria. The percentage of START criteria present in identified DRPs was higher than the percentage of STOPP criteria (13 vs. $5.7 \%, p=0.001$ ).
Table 1 Baseline characteristics of participants ( $\geq 65$ years and $\geq 5$ drugs) $n=457$

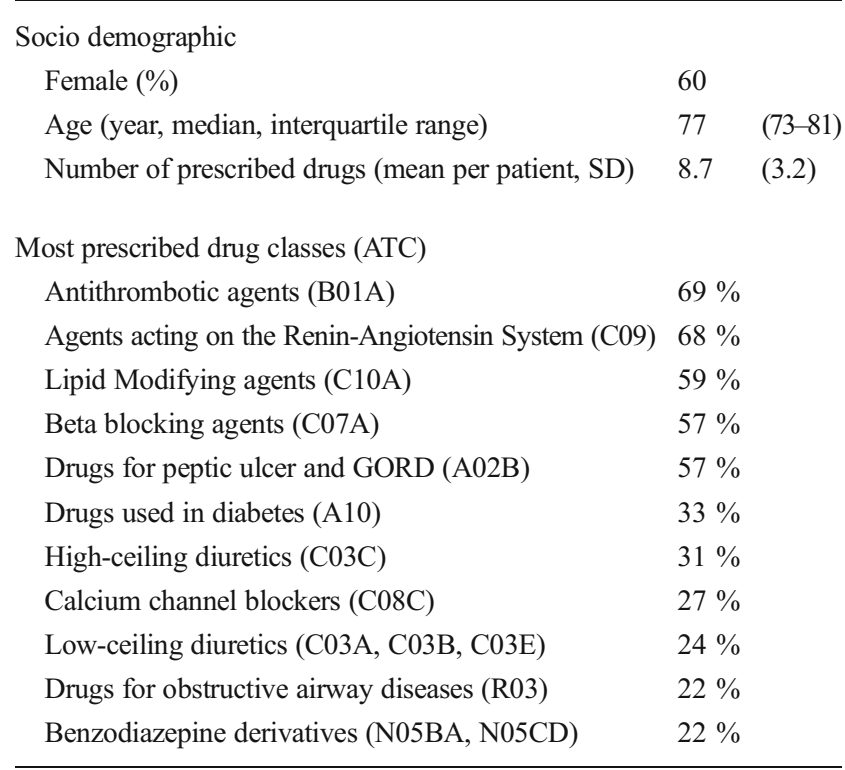

ATC Anatomical Therapeutic Chemical Classification System

The majority of STOPP criteria was associated with DRP type "drug selection" (59/94, $63 \%$ ), whereas START criteria were associated with DRP type "undertreated" (205/214, $96 \%$ ). Both "undertreatment" and drug selection were more frequently identified in the absence of either STOPP or START criteria. Seventy-nine percent of the DRP type drug selection and $57 \%$ of the DRP type undertreated did not comprise the criteria. The most common DRP type related with the recommendation to cease a drug was "no indication apparent" (186/338, $55 \%)$. The most common DRP type related with the recommendation to add a drug was an untreated symptom that emerged from the patient interview, e.g. pain, itching or shortness of breath $(32 / 275,12 \%)$.

\section{Implementation rate of recommendations associated with STOPP/START criteria}

Thirty-five percent of DRPs were associated with a recommendation to cease, replace or add a drug. The implementation rate for recommendations associated with STOPP criteria was higher compared to recommendations associated with START criteria ( 56 vs. $39 \%, p=0.005$ ). Both implementation rates of recommendations associated with STOPP and START criteria were lower compared to recommendations not associated with STOPP or START criteria $(66 \%, p=0.047$ and $p<0.001$, respectively, Table 3).

STOPP criteria were applicable to 79 of 338 recommendations to cease a drug $(23 \%)$. The implementation rate for STOPP criteria was not different compared to other recommendations to cease a drug ( 58 vs. $51 \%, p=0.23$ ). START criteria 
Table 2 Classification of identified DRPs by STOPP and START criteria

\begin{tabular}{|c|c|c|c|c|c|c|c|}
\hline \multirow[t]{2}{*}{ DRP type and subtype } & \multirow[b]{2}{*}{$N$} & \multicolumn{2}{|c|}{ Not identified by STOPP/START } & \multicolumn{2}{|c|}{ Identified by STOPP } & \multicolumn{2}{|c|}{ Identified by START } \\
\hline & & $N$ & $(\%)^{\mathrm{b}}$ & $N$ & $(\%)^{\mathrm{b}}$ & $N$ & $(\%)^{\mathrm{b}}$ \\
\hline $\mathrm{D}$ (rug selection) & 303 & 239 & (79) & 59 & (19) & 5 & (2) \\
\hline Duplication & 20 & $3^{\mathrm{a}}$ & $(15)$ & 17 & $(85)$ & - & - \\
\hline Drug interaction & 11 & 10 & $(91)$ & 1 & (9) & - & - \\
\hline Contra-indication apparent & 16 & 7 & $(44)$ & 7 & $(44)$ & 2 & $(12)$ \\
\hline No indication apparent & 256 & 219 & $(86)$ & 34 & $(13)$ & 3 & (1) \\
\hline $\mathrm{O}($ ver or underdose $)$ & 200 & 199 & (99) & 1 & (1) & - & - \\
\hline Prescribed dosage too high & 64 & 63 & (99) & 1 & (1) & - & - \\
\hline Prescribed dosage too low & 52 & 52 & $(100)$ & - & - & - & - \\
\hline Incorrect or unclear dosing instructions & 84 & 84 & $(100)$ & - & - & - & - \\
\hline $\mathrm{C}($ ompliance $)$ & 142 & 139 & (98) & 1 & (1) & 2 & (1) \\
\hline Taking too little & 72 & 69 & $(96)$ & 1 & (1) & 2 & (3) \\
\hline Taking too much & 8 & 8 & $(100)$ & - & - & - & - \\
\hline Difficulty using dosage form & 62 & 62 & $(100)$ & - & - & - & - \\
\hline U(ndertreated) & $\mathbf{5 0 7}$ & 289 & (57) & 13 & (3) & 205 & (40) \\
\hline Condition undertreated & 380 & 215 & $(57)$ & 12 & (3) & 153 & $(40)$ \\
\hline Condition untreated & 127 & 74 & $(58)$ & 1 & (1) & 52 & $(41)$ \\
\hline $\mathrm{M}$ (onitoring) & 222 & 221 & (99) & - & - & 1 & (1) \\
\hline Laboratory monitoring & 152 & 152 & $(100)$ & - & - & - & - \\
\hline Non-laboratory monitoring & 70 & 69 & (99) & - & - & 1 & (1) \\
\hline $\mathrm{E}$ (ducation or information) & 62 & 62 & (100) & - & - & - & - \\
\hline Disease management or advice & 62 & 62 & $(100)$ & - & - & - & - \\
\hline $\mathrm{N}($ on-clinical) & 55 & 54 & (98) & 1 & (2) & & \\
\hline Other & 55 & 54 & $(98)$ & 1 & $(2)$ & & \\
\hline $\mathrm{T}$ (oxicity) & 165 & 145 & (88) & 19 & (11) & 1 & (1) \\
\hline Toxicity, allergic reaction or adverse effect present & 165 & 145 & $(88)$ & 19 & $(11)$ & 1 & (1) \\
\hline Overall & 1656 & 1348 & (81) & 94 & (6) & 214 & (13) \\
\hline
\end{tabular}

Bold entries represent the most important outcomes

$N$ number

${ }^{a}$ These three DRPs were mistakenly coded duplicate medication by the pharmacists. DRPs were (1) codeine and oxycodone (pseudo-duplicate), (2) allopurinol and colchicine (overtreatment), and (3) two different dosages of doxazosine were in use simultaneously (dose too high)

${ }^{\mathrm{b}}$ The percentage within DRP type or subtype

were applicable to 197 of 275 recommendations to add a drug (72\%). The implementation rate for the subgroup START criteria recommendations was lower compared to other recommendations to add a drug ( 38 vs. $54 \%, p=0.02$ ) (Table 3 ).

\section{Prevalence and types of STOPP/START criteria}

STOPP criteria were present in 80 patients $(17 \%)$. Sixty-nine patients had one potentially inappropriate drug, and 11 had more than one. START criteria were present in 163 patients (36\%). One hundred twenty-two patients had one potential prescribing omission and 41 had more than one.

Nine types of STOPP criteria accounted for $82 \%$ of the total and 25 of the 65 available types of STOPP criteria were present. The most prevalent STOPP criteria were duplicate drug classes $(N=19,20 \%)$, benzodiazepines $(N=12,13 \%)$ and vasodilator drugs $(N=12,13 \%)$ (Table 4). 
Table 3 Comparison of prevalence and implementation rate of recommendations to stop, add or replace a drug, associated with STOPP/START criteria and implicit criteria

\begin{tabular}{|c|c|c|c|c|c|c|c|c|}
\hline \multirow[t]{2}{*}{ Type of recommendation } & \multicolumn{3}{|c|}{ No STOPP/START } & \multicolumn{2}{|c|}{ STOPP } & \multicolumn{2}{|c|}{ START } & \multirow[t]{2}{*}{$P$ value } \\
\hline & $N$ & & IR & $N$ & IR & $N$ & IR & \\
\hline Cessation of drug & 259 & $\mathbf{5 1} \%$ & & 79 & $58 \%$ & - & - & 0.23 \\
\hline Addition of a drug & 78 & $\mathbf{5 4} \%$ & & - & - & 197 & $38 \%$ & 0.02 \\
\hline \multirow[t]{3}{*}{ Replacement of drug } & 138 & $51 \%$ & & & & & & \\
\hline & & & & 15 & $47 \%$ & - & - & 0.75 \\
\hline & & & & - & - & 17 & $53 \%$ & 0.83 \\
\hline \multirow[t]{2}{*}{ Other } & 873 & $75 \%$ & & - & - & - & - & - \\
\hline & 1348 & $66 \%$ & & & & & & \\
\hline \multirow[t]{2}{*}{ Total } & & & & 94 & $56 \%$ & - & - & 0.047 \\
\hline & & & & - & - & 214 & $39 \%$ & $<0.001$ \\
\hline
\end{tabular}

Bold entries represent the most important outcomes

$N$ number, IR implementation rate

Ten START criteria accounted for $89 \%$ of the total, and 18 of the 22 available START criteria were present. The most common START criteria were calcium and vitamin D in osteoporosis $(N=58,27 \%)$, statins in coronary, cerebral or peripheral vascular disease $(N=31,14 \%)$, and $\beta$-blockers in angina, acute MI or heart failure ( $N=20,9 \%)$ (Table 5$)$.

\section{Discussion}

This study shows that the majority $(81 \%)$ of DRPs identified by pharmacists during a clinical medication review was not associated with STOPP/START criteria. START criteria identified twice as much DRPs compared to STOPP criteria. In contrast, the implementation rate of recommendations originating from STOPP criteria was higher compared to recommendations originating from START criteria. Recommendations not originating from STOPP/START criteria, however, had a higher implementation rate than both STOPP and START criteria.

The majority of DRPs (65\%) identified during medication review is not associated with recommendations to cease, replace or add a drug, and could therefore not be detected with STOPP/START criteria. Furthermore, only half of the recommendations to cease or add a drug are associated with STOPP/ START criteria in this study. In particular, only $23 \%$ of all recommendations to cease a drug comprised a STOPP criterion. The most important reason to cease a drug was no indication apparent for a drug. The majority of DRPs can therefore only be detected by a structural assessment of the patient's medicines and diagnoses using the implicit criteria. These findings underline the importance of using implicit criteria for medication review and education of the community pharmacist to develop the required medication review skills to use them [26].
Table 4 Implementation rates of ten most frequent potentially inappropriate medications according to STOPP criteria

\begin{tabular}{|c|c|c|}
\hline Inappropriate medication & $N$ & $\operatorname{IR}(\%)$ \\
\hline Any duplicate drug class prescription & 19 & 47 \\
\hline Drugs that adversely affect fallers: Benzodiazepines & 12 & 67 \\
\hline Drugs that adversely affect fallers: Vasodilator drugs & 12 & 50 \\
\hline Long-term (i.e. $>1$ month), long-acting benzodiazepines & 7 & 71 \\
\hline Aspirin-not indicated & 6 & 33 \\
\hline Oestrogens without progestagen in patients with intact uterus & 5 & 100 \\
\hline NSAID with heart failure & 5 & 80 \\
\hline $\begin{array}{l}\text { Long-term NSAID or colchicine for chronic treatment of gout - no } \\
\text { contraindication to allopurinol }\end{array}$ & 5 & 80 \\
\hline$\beta$-Blockers and frequent hypoglycaemic episodes & 3 & 67 \\
\hline Long-term opiates in those with recurrent falls & 2 & 50 \\
\hline
\end{tabular}

$N$ number, $I R$ implementation rate 
Table 5 Implementation rates of ten most frequent potential prescribing omissions according to START criteria

\begin{tabular}{|c|c|c|}
\hline Omitted medication - medical condition & $N$ & $\operatorname{IR}(\%)$ \\
\hline Calcium and vitamin D supplement—osteoporosis & 58 & 57 \\
\hline Statin therapy-history of coronary, cerebral or peripheral vascular disease & 31 & 26 \\
\hline$\beta$-Blocker-angina, acute MI or heart failure & 20 & 15 \\
\hline Proton pump inhibitor-ASA $(\leq 100 \mathrm{mg})$ and $>80$ years, NSAID and $>70$ years or reflux ${ }^{\mathrm{a}}$ & 19 & 79 \\
\hline Bisphosphonates - corticosteroids or osteoporosis & 16 & 13 \\
\hline Statin therapy-diabetes mellitus & 13 & 23 \\
\hline ACE inhibitor-heart failure & 9 & 44 \\
\hline Metformin - type 2 diabetes or metabolic syndrome & 9 & 22 \\
\hline ACE inhibitor or angiotensin receptor blocker — diabetes with nephropathy & 8 & 50 \\
\hline Antihypertensive therapy—systolic blood pressure $>160 \mathrm{mmHg}$ & 8 & 25 \\
\hline
\end{tabular}

$N$ number, IR implementation rate

${ }^{\mathrm{a}}$ This START criterion is an adapted version of the original STOPP criterion, as used in the Dutch guidelines [8]
START criteria were applicable to $36 \%$ of patients which was considerably higher than in the study of Ryan et al. (23\%) [27]. Eighteen of 22 criteria accounted for the prescribing omissions in our study, while this was 15 in the study of Ryan [27]. The high prevalence of START criteria in our study together with the high proportion of recommendations to add a drug associated with START criteria suggests a good practical applicability of this tool for older patients with polypharmacy in primary care. Other reasons to add a drug were mainly based on the complaints of the patient that emerged from the interview. These problems are diverse and could not easily be converted into a START criterion.

The implementation rate of recommendations associated with STOPP was comparable to other recommendations to cease a drug. On the contrary, recommendations to add a new drug based on START were less frequently implemented compared to other recommendations to add a drug. Especially, recommendations to add cardiovascular drugs (e.g. statins, ACE inhibitors and beta-blockers) were poorly implemented. It is likely that GPs are cautious to change cardiovascular treatment of patients who are concurrently seeing a specialist. Furthermore, non-acceptance may be caused by the fact that patients previously experienced adverse effects on these drugs. Although these adverse effects are probably not always that serious that rechallenge is unacceptable, patients will often be reluctant to restart such drugs. Finally, GPs may be reluctant to add preventive drugs in the oldest old, because risk factors such as high cholesterol levels and hypertension for those patients may not be related to mortality [28, 29]. On the contrary, addition of proton pump inhibitors and, to a lesser extent, calcium and vitamin D had high implementation rates. These drugs are characterised by a direct effect or by the absence of serious adverse effects.

Our study had several strengths. First of all, the elaborate description of DRPs and recommendations by the pharmacists enabled retrospective identification of STOPP/START criteria. Second, we used data from routinely performed medication reviews involving a high number of community pharmacists, GPs and patients. The results are therefore likely to be representative for daily clinical practice in primary care.

There were some limitations to the study. First, we could not directly apply the STOPP/START criteria because the researchers, unlike the pharmacists, did not have access to medical records (diagnoses and laboratory values). Therefore, the study design did not allow for a direct comparison of a strategy purely based on STOPP/START criteria and a strategy based on implicit criteria. Although for a limited number of STOPP criteria, clinical information is not required, and access to the full clinical record is recommended for the majority of STOPP and START criteria [30].

Despite this, STOPP criteria in our study were applicable to $18 \%$ of the patients, which is slightly lower than the findings of Ryan et al. in a comparable primary care population [27]. In our study, 25 of 65 STOPP criteria were used, which is comparable to the study of Ryan et al. using 28 STOPP criteria [27, 30].

Second, the pharmacists who performed the medication reviews did not have specific training in the application of STOPP and START criteria. However, the pharmacists were considered to have sufficient knowledge of the guidelines underlying these explicit criteria, based on the training programme and monthly web conferences. Still, it is likely that applying the STOPP/START criteria on the medication data of the original population selected for medication review would also have identified some DRPs that now have been missed by the pharmacist. Thirdly, the implementation rate of recommendations was based on self-report by the community pharmacists and not on measurement of medication changes in dispensing records. Finally, by including only patients taking five or more medications, bias could be introduced by potential underestimation of prescribing omissions as detected by START criteria.

Although STOPP/START criteria were present in a minority of all DRPs identified, especially, START criteria do seem 
applicable as a screening tool for medication review in primary care. It has been suggested to incorporate STOPP and START in existing information systems in primary care [27]. Such automated systems could facilitate medication review but cannot replace a systematic approach using implicit criteria. Finally, explicit criteria will remain susceptible to changes, which are shown by the recently published second version of the STOPP/START criteria [31]. Future research should further establish the applicability of STOPP/START criteria in medication review by incorporation of the tool into the intervention.

\section{Conclusion}

This study shows a higher prevalence of START criteria compared to STOPP criteria in identified DRPs of communitydwelling older patients, while STOPP criteria are implemented more frequently. Although STOPP/START criteria identify an important number of DRPs, the majority of DRPs identified during medication review was not associated with STOPP/START criteria. When used, START criteria may have a higher practical applicability compared to the extensive list of STOPP criteria for medication review in primary care. These findings suggest that health care providers cannot solely depend on the STOPP/START criteria to identify DRPs in primary care.

Acknowledgements The authors like to thank all 13 participating community pharmacies of cooperation Connecting Care.

Funding The performed medication reviews in this study were reimbursed by the health insurance company VGZ (Stichting Volksgezondheidszorg). The study itself received no external funding.

Conflict of interest All authors declare that they have no competing interests that are directly relevant to the content of this study.

Authors' contributions All authors designed the study. HFK and SV analysed the results. All authors interpreted the results, contributed to writings revisions and approved the final manuscript.

Open Access This article is distributed under the terms of the Creative Commons Attribution 4.0 International License (http:// creativecommons.org/licenses/by/4.0/), which permits unrestricted use, distribution, and reproduction in any medium, provided you give appropriate credit to the original author(s) and the source, provide a link to the Creative Commons license, and indicate if changes were made.

\section{References}

1. Willcox SM, Himmelstein DU, Woolhandler S (1994) Inappropriate drug prescribing for the community-dwelling elderly. JAMA 272:292-6
2. Beers MH (1997) Explicit criteria for determining potentially inappropriate medication use by the elderly. An update. Arch Intern Med 157:1531-6

3. Hanlon JT, Schmader KE, Ruby CM, Weinberger M (2001) Suboptimal prescribing in older inpatients and outpatients. J Am Geriatr Soc 49:200-9

4. Castelino RL, Bajorek BV, Chen TF (2009) Targeting suboptimal prescribing in the elderly: a review of the impact of pharmacy services. Ann Pharmacother 43:1096-106

5. Spinewine A, Schmader KE, Barber N, Hughes C, Lapane KL, Swine C, Hanlon JT (2007) Appropriate prescribing in elderly people: how well can it be measured and optimised? Lancet 370:173-84

6. Leendertse AJ, de Koning FH, Goudswaard AN, Jonkhoff $\mathrm{AR}$, van den Bogert SC, de Gier HJ, Egberts TC, van den Bemt PM (2011) Preventing hospital admissions by reviewing medication (PHARM) in primary care: design of the cluster randomised, controlled, multi-centre PHARMstudy. BMC Health Serv Res 11:4

7. Hepler CD, Strand LM (1990) Opportunities and responsibilities in pharmaceutical care. Am J Hosp Pharm 47:533-43

8. Windsant-van V, den Tweel AM, Verduijn MM, Derijks HJ, van Marum RJ (2012) Detection of inappropriate medication use in the elderly; will the STOPP and START criteria become the new Dutch standards? Ned Tijdschr Geneeskd 156:A5076

9. Bryant LJ, Coster G, Gamble GD, McCormick RN (2011) The General Practitioner-Pharmacist Collaboration (GPPC) study: a randomised controlled trial of clinical medication reviews in community pharmacy. Int J Pharm Pract 19:94-105

10. Sellors J, Kaczorowski J, Sellors C, Dolovich L, Woodward C, Willan A, Goeree R, Cosby R, Trim K, Sebaldt R, Howard M, Hardcastle L, Poston J (2003) A randomized controlled trial of a pharmacist consultation program for family physicians and their elderly patients. CMAJ 169:17-22

11. Sorensen L, Stokes JA, Purdie DM, Woodward M, Elliott R, Roberts MS (2004) Medication reviews in the community: results of a randomized, controlled effectiveness trial. Br J Clin Pharmacol 58:648-64

12. Kwint HF, Faber A, Gussekloo J, Bouvy ML (2011) Effects of medication review on drug-related problems in patients using automated drug-dispensing systems: a pragmatic randomized controlled study. Drugs Aging 28:305-14

13. Beers MH, Ouslander JG, Rollingher I, Reuben DB, Brooks J, Beck JC (1991) Explicit criteria for determining inappropriate medication use in nursing home residents. UCLA Division of Geriatric Medicine. Arch Intern Med 151:1825-32

14. Fick DM, Cooper JW, Wade WE, Waller JL, Maclean JR, Beers MH (2003) Updating the Beers criteria for potentially inappropriate medication use in older adults: results of a US consensus panel of experts. Arch Intern Med 163:2716-24

15. American Geriatrics Society, American Geriatrics Society 2012 Beers Criteria Update Expert Panel (2012) American Geriatrics Society updated Beers Criteria for potentially inappropriate medication use in older adults. J Am Geriatr Soc 60:616-31

16. Levy HB, Marcus EL, Christen C (2010) Beyond the beers criteria: a comparative overview of explicit criteria. Ann Pharmacother 44: 1968-75

17. O'Mahony D, Gallagher PF (2008) Inappropriate prescribing in the older population: need for new criteria. Age Ageing $37: 138-41$

18. Laroche ML, Charmes JP, Merle L (2007) Potentially inappropriate medications in the elderly: a French consensus panel list. Eur J Clin Pharmacol 63:725-31

19. Gallagher P, Ryan C, Byrne S, Kennedy J, O'Mahony D (2008) STOPP (Screening Tool of Older Person's Prescriptions) and 
START (Screening Tool to Alert doctors to Right Treatment). Consensus validation. Int J Clin Pharmacol Ther 46:72-83

20. Gallagher P, Lang PO, Cherubini A, Topinkova E, Cruz-Jentoft A, Montero Errasquin B, Madlova P, Gasperini B, Baeyens H, Baeyens JP, Michel JP, O’Mahony D (2011) Prevalence of potentially inappropriate prescribing in an acutely ill population of older patients admitted to six European hospitals. Eur J Clin Pharmacol 67:1175-88

21. Gallagher P, O'Mahony D (2008) STOPP (Screening Tool of Older Persons' potentially inappropriate Prescriptions): application to acutely ill elderly patients and comparison with Beers' criteria. Age Ageing 37:673-9

22. Ryan C, O'Mahony D, Byrne S (2009) Application of STOPP and START criteria: interrater reliability among pharmacists. Ann Pharmacother 43:1239-44

23. Williams M, Peterson GM, Tenni PC, Bindoff IK, Stafford AC (2012) DOCUMENT: a system for classifying drug-related problems in community pharmacy. Int J Clin Pharm 34:43-52

24. Williams M, Peterson GM, Tenni PC, Bindoff IK, Curtain C, Hughes J, Bereznicki LR, Jackson SL, Kong DC, Hughes JD (2011) Drug-related problems detected in Australian community pharmacies: the PROMISe Trial. Ann Pharmacother 45:1067-76
25. Kwint HF, Faber A, Gussekloo J, Bouvy ML (2012) The contribution of patient interviews to the identification of drug-related problems in home medication review. J Clin Pharm Ther 37:674-80

26. Niquille A, Lattman C, Bugnon O (2010) Medication reviews led by community pharmacists in Switzerland: a qualitative survey to evaluate barriers and facilitators. Pharm Pract 8:35-42

27. Ryan C, O’Mahony D, Kennedy J, Weedle P, Byrne S (2009) Potentially inappropriate prescribing in an Irish elderly population in primary care. Br J Clin Pharmacol 68:936-47

28. Weverling-Rijnsburger AW, Jonkers IJ, van Exel E, Gussekloo J, Westendorp RG (2003) High-density vs low-density lipoprotein cholesterol as the risk factor for coronary artery disease and stroke in old age. Arch Intern Med 163:1549-54

29. van Bemmel T, Gussekloo J, Westendorp RG, Blauw GJ (2006) In a population-based prospective study, no association between high blood pressure and mortality after age 85 years. J Hypertens 24:287-92

30. Ryan C, O'Mahony D, O'Donovan DO, O'Grady E, Weedle P, Kennedy J, Byrne S (2013) A comparison of the application of STOPP/START to patients' drug lists with and without clinical information. Int J Clin Pharm 35:230-5

31. O'Mahony D, O'Sullivan DO, Byrne S, O'Connor MN, Ryan C, Gallagher P (2015) STOPP/START criteria for potentially inappropriate prescribing in older people: version 2. Age Ageing 44:213-8 